\title{
The siege of Leningrad (1941-1944): memories of the survivors who have lived through the trauma
}

\author{
Marina A. Gulina \\ City University, London, England, \\ Lomonosov Moscow State University, Moscow, Russia
}

\begin{abstract}
The article has discussed the Leningrad Siege (1941-1944), focusing on the individual and collective memories of survivors who had lived through that trauma during their childhood. Thus far there has been no psychological investigation of the feelings of extreme deprivation caused by that Siege, despite the reams of material published on Leningrad under siege. To deal with this shortfall, the critique has considered the effect of that experience on the future lives of the people concerned. The basic methodology, the paper maintains, combined quantitative and qualitative approaches and involved a comparison of two equal-sized groups: the experimental group, comprising 60 war survivors who lived through the Siege; and the control group, comprising 60 war survivors who were evacuated from Leningrad during the Siege and consequently did not experience the trauma. The review related that the groups were matched by age and by gender distribution. Data for the Interpretative Phenomenological Analysis-based qualitative analysis (QA) were collected according to psychometric measures (containing scales for depression, general satisfaction with life, and stress) applied in semi-structured interviews. The QA, for its part, used methods such as correlation, factor- and cluster-analysis to measure data segments. The nature of the suffering and the persistence of the human threat (past and present) were reconstructed within the framework of the psychological experiences (under extreme conditions) faced by the experimental group. The report, in conclusion, has stated that these experiences were evaluated via psychoanalytic tools dealing with child development, mourning and symbolization of traumatic events. These enabled it to identify psychological phenomena such as child grief and the impact of trauma on the adult life of the former Siege victims.
\end{abstract}

Key words: Siege, strain trauma, cumulative trauma, child development, attachment, traumatic disorganization, resilience

\section{Historical Background}

The Siege of Leningrad lasted from 1941-1944 after advancing German troops had virtually surrounded the city. According to official data, some 2.8 million people, including 400,000 children, were trapped in the city at the outset of the 
Siege. The initial winter was the most difficult, with intensive aerial attacks and prolonged artillery bombardments causing electric failures and residential heating blackouts. Under these conditions, the interior walls became covered with white frost. In January 1942, during the first winter, temperatures plummeted to minus forty Celsius, freezing the municipal water pipes and disrupting the potable water supply. To overcome the water shortfall, people either melted snow or drew water from holes hacked in the ice of the frozen Neva River and the nearby canals. As of Nov. 20, 1941, the official daily rations had fallen to 250 grams of bread for essential workers vs 125 grams for non-essential workers and dependents (including children), i.e. little more than a slice of bread. The dead accumulated in the streets and homes, with many of the starving even lacking the energy to speak. Information about what was happening was extremely limited; it remains an issue of historical conjecture why the municipality had provided only minimal food supplies. Dmitri Likhachov wrote, "Germany prepared for the Siege of Leningrad, expecting the urban authorities to surrender" (Likhachov, 1999, p.161).

\section{Design of the Study}

The present study collected participants' memories of their wartime experiences, with the long-term objective of gaining insight into how they had felt during the Leningrad Siege and whether the traumatic incidents had affected their personalities. A total of 120 elderly people were interviewed for the research paper in 2004, with these subdivided into two major groups: those who had lived in Leningrad during the Siege (the experimental group) and those who had been evacuated and experienced the war elsewhere (the control group). Both groups - 37 men and 83 women - were identical in terms of age and gender distribution. The data obtained were subjected to a quantitative analysis (of correlation, factor and cluster) and a qualitative analysis (combination of content analysis and interpretative phenomenological analysis), with particular attention paid to the differences between individual experiences of the two groups. As in all studies of this kind, the participants were questioned about traumatic events they had experienced when they were relatively young. Many participants had vivid memories of the events, but experienced extreme difficulty in recalling them. Almost $50 \%$ of the people who had at first agreed to take part in the study eventually bowed out as a result of the extreme emotions attached to their memories. In other words, even sixty years after the event, many blockade survivors could not discuss it openly. Their response was similar to that of prisoners from German concentration camps, for whom silence and repression of trauma often remained the only bearable options. The protocol's questions concerned factual details (the birthdate, family members, and living conditions) during the blockade while the interviewees remained in Leningrad; and wartime memories (earliest childhood recollections and memories of the period in the immediate aftermath of the war). 


\section{Semi-structured Interview Questions}

(Note: questions for the control group have been reformulated as questions about the war in general):

1. Please describe in a few words your mother or the person who cared for you in that role.

2. Please describe in a few words your father or the person who cared for you in that role.

3. Why did Mama praise and scold you during your childhood?

4. Why did Papa praise and scold you for during your childhood?

5. What was your favorite book?

6. Which was your favorite literary character?

7. What was the most difficult thing for you during the Siege?

8. What was your happiest moment during the Siege (apart from its ending)?

9. What do you remember dreaming about during the Siege?

10. What did you know about the enemy?

11. What helped you survive?

12. Did your attitude towards yourself change after the war?

13. Did your attitude towards people in general change after the war?

14. Did your attitude toward food change after the war?

15. Which personality traits do you think helped you overcome difficulties in your life?

In addition, several questions were based on three short scales: Stress Scale, Scale of General Satisfaction with Life, Depression Scale.

\section{Quantitative Analysis: Findings}

Age and war trauma: At the outbreak of the war, the average age of children in the control group was 6.2 years versus 8.6 years in the experimental group (the differences are statistically significant, $\mathrm{p}<0.001$ ), though the concept of age partly loses its significance for Siege children. "We were not children, but tiny old men and women. We played at war and at being nurses. Smiles were very rare. All of us were equally skinny in the sauna. We went to a common sauna (this would have been completely out of the question prior to the war - M.G.). There was no gender, no age; it would not have been possible to distinguish a granny from a girl or a boy" (participant A.N.). Both groups of children suffered enormously, but the answers given by the participants for the question, 'What was the most difficult thing for you during the Siege (experimental group) or war (control group)?', were different (Table 1). 
Table 1. Hierarchy of frequencies of 'most difficult thing' (question № 7) for both the experimental and the control groups $(\mathrm{n}=120)$

\begin{tabular}{|c|c|c|}
\hline \multicolumn{2}{|r|}{ Rank Control Group } & \multirow[t]{2}{*}{ Experimental Group } \\
\hline № 1 & $\begin{array}{l}\text { Worry about war events, about } \\
\text { success of Soviet Army }\end{array}$ & \\
\hline № 2 & Hunger & Bombing \\
\hline № 3 & Cold & Visibility of death \\
\hline № 4 & $\begin{array}{l}\text { Disorder in life during the evacuation, } \\
\text { lack of suitable clothing, lack of toys }\end{array}$ & $\begin{array}{l}\text { Death or fear of death for members } \\
\text { of child's family }\end{array}$ \\
\hline № 5 & $\begin{array}{l}\text { Difficulties in socializing } \\
\text { in a new place }\end{array}$ & $\begin{array}{l}\text { Fear of being killed or harmed } \\
\text { by other people }\end{array}$ \\
\hline № 6 & Loss of significant intimates (death) & Other losses \\
\hline № 7 & Separation from intimates & Cold \\
\hline № 8 & Father's arrest & Darkness \\
\hline № 9 & $\begin{array}{l}\text { Things beyond your capacity } \\
\text { (e.g. 'long walk to school') }\end{array}$ & Fear of staying alone \\
\hline № 10 & Threat to studies & Helplessness \\
\hline № 11 & Bombing & \\
\hline
\end{tabular}

The evacuated children (control group) were not exposed to the threat of being killed or harmed by other starving people; nor did they suffer from constant darkness which, as the interviews showed, ranked as an important source of suffering. On the other hand, the children who stayed in Leningrad (experimental group) did not have problems in adjusting to a new place; they had already left behind their friends, books, clothes, potential resources, personal belongings, etc. However, they were often isolated, staying alone in their flats, waiting for their care-givers to return with food, and, when they did communicate with other children, found little energy left to do so. As the levels of suffering increased, so did the feelings of isolation. If, for the control group, the challenge was to adjust to the loss of their earlier life patterns and to new circumstances, for the experimental group, the issue was simply to survive. Their mother (or sometimes father) was a central figure in their battle with visible death. In addition, the Siege children were exposed to death as a daily occurrence: they saw the corpses of neighbors, family members, classmates, strangers on the street, and trucks filled with naked frozen bodies.

To cope with that task, these children had to display extraordinary levels of strength, responsibility and social adjustment.

The quantitative analysis was conducted with the following list of variables: 


\section{Independent variables:}

№ 1. Group (Siege or Evacuated)

№ 2. Gender

\section{Dependent variables:}

№ 3. Age at outbreak of the war

№ 4. Length of Siege experience (in months)

№ 5. Number of family members at outbreak of the war

№ 6. Number of relatives lost as a result of the war

№ 7. Two parents or one at outbreak of the war

№ 8. Number of mentioned tragic events connected with the war or Siege

№ 9. Number of 'significant others' in earliest childhood re-collection

№ 10. Age at time of earliest childhood re-collection

№ 11. Polarity of earliest childhood re-collection (positive, negative, neutral)

№ 12. Resilience under stress

№ 13. General Life Satisfaction

№ 14. Depression

№ 15. Number of relatives lost for reasons unconnected with bombing or Siege during childhood and adolescence

№ 16. Number of mentioned tragic events unconnected with bombing or Siege during childhood or adolescence

The correlation analysis (based on Spearman's and Pearson's coefficients) has revealed numerous links between the Siege experience and other variables. It also has unveiled significant positive correlations between the length of the Siege experience and the number of relatives lost as a result of the war (var. № $6: r=0.33$; $\mathrm{p}<0.001$ ); the number of mentioned tragic events (var. № 8: $\mathrm{r}=0.29 ; \mathrm{p}<0.01$ ); the number of 'significant others' in early childhood re-collections (var. № 9: $r=0.29$; $\mathrm{p}<0.01$ ); and the resilience under stress (var. № 12 : $\mathrm{r}=0.30 ; \mathrm{p}<0.01$ ). By contrast, the correlation analysis has unveiled significant negative correlations between the length of the Siege experience and the time of the earliest childhood re-collection (var. № 10: $\mathrm{r}=0.32, \mathrm{p}<0.01$ ); and the number of mentioned tragic events unrelated to the bombing or the Siege (var. № 16: $\mathrm{r}=0.35 ; \mathrm{p}<0.001$ ); and depression (var. № 14: $\mathrm{r}=0.30, \mathrm{p}<0.01$ ).

Therefore, the correlation analysis' chief, if unexpected, interpretable results associated longer deprivation under Siege conditions with a higher level of stress resilience and a lower level of depression in the survivors' present life. In essence, some Siege survivors mentioned in their interviews that they have achieved in the 'balance of their life an additional token, second chance or second life' (M.F.). But 'nothing could be compared with the Siege experience, which represented for the Siege survivors the most extreme condition that they could stand' (B.R.).

In addition, the interviews assessed those participants who claimed, "I still cry at night"; "I am still hungry"; "I still feel a horrible dependence on shopkeepers"; "I can't stand the loud noise of fireworks; and "I become panicky as I was during the air raids"? 
Table 2. Cluster analysis ('The nearest neighbor' method) for the whole sample ( $\mathrm{n}=112$ from initial 120).

\begin{tabular}{|c|c|c|c|c|c|}
\hline Variable $\mathbf{N}$ & 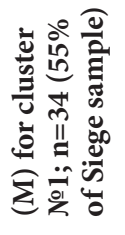 & 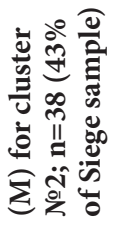 & 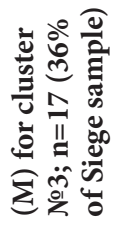 & 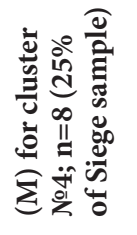 & 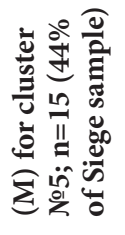 \\
\hline №3 Age at outbreak of war & 4 & 9 & 10 & 7 & 7 \\
\hline $\begin{array}{l}\text { №4 Length of Siege experi- } \\
\text { ence (in months) }\end{array}$ & 17 & 12 & 15 & 7 & 9 \\
\hline $\begin{array}{l}\text { №5 Size of family at out- } \\
\text { break of war }\end{array}$ & 5 & 5 & 4 & 5 & 4 \\
\hline $\begin{array}{l}\text { №6 } 6 \text { Number of relatives lost } \\
\text { as a result of war/Siege }\end{array}$ & 0,6 & 1 & 1,3 & I 1,3 & 0,6 \\
\hline $\begin{array}{l}\text { №7 Family intact/not intact } \\
\text { at outbreak of war }\end{array}$ & 1 & 1 & 0,7 & 0,5 & 1 \\
\hline $\begin{array}{l}\text { №8 Number of mentioned } \\
\text { tragic events connected with } \\
\text { the war or Siege }\end{array}$ & 5 & 6 & 10 & 9 & 5 \\
\hline $\begin{array}{l}\text { №9 Number of significant } \\
\text { others in first childhood } \\
\text { memory }\end{array}$ & 1 & 2 & 3 & 1 & 2 \\
\hline $\begin{array}{l}\text { №10 Age at time of first } \\
\text { childhood memory }\end{array}$ & 4 & 5 & 6 & 4,5 & 4,2 \\
\hline $\begin{array}{l}\text { № } 11 \text { Polarity of first child- } \\
\text { hood recollection }\end{array}$ & 4 & 4 & 0 & 2 & 3 \\
\hline №12 Resilience under stress & 4 & 7 & 2 & 4 & 4 \\
\hline №13 General life satisfaction & 20 & 24 & 16 & 22,5 & 19 \\
\hline №14 Depression & 4 & 3 & 6 & 4 & 5 \\
\hline $\begin{array}{l}\text { № } 15 \text { Number of relatives } \\
\text { lost as a result of political } \\
\text { arrests }\end{array}$ & 0 & 0,1 & 0,9 & 2,2 & 0 \\
\hline $\begin{array}{l}\text { №16 Number of relatives } \\
\text { lost for reasons uncon- } \\
\text { nected with bombings or } \\
\text { Siege during childhood or } \\
\text { adolescence }\end{array}$ & 0,4 & 0,25 & 0,2 & 1,5 & 0,2 \\
\hline $\begin{array}{l}\text { №17 Number of mentioned } \\
\text { tragic events during child- } \\
\text { hood or adolescence that } \\
\text { were unconnected with war }\end{array}$ & 3 & 2 & 2 & 3 & 2 \\
\hline
\end{tabular}


This apparent contradiction, which challenged the initial design of the study (its division into experimental and control groups), led to the use of cluster analysis to unveil potentially new participant sub-samples. Table 2 , for instance, summarized the results of this analysis. One hundred and twelve participants were found to constitute five clusters, with members of both initial groups (experimental and control) found in varying proportions in each cluster.

The cluster analysis comprises three groups that constitute the major part of the sample of war survivors (both control and experimental groups):

- 34 rather small children (4 years old on average) at the outbreak of the war, who remained in Leningrad a long time (17 months on average). They showed mild levels of resilience under stress, depression and general life satisfaction in old age (at the time of their interviews);

- 38 older children (9 years old on average), who remained in Leningrad for a shorter period (12 months on average). They showed the highest level of resilience under stress, a low level of depression and a high level of general life satisfaction in old age (at the time of their interviews).

- 17 slightly older children (10 years old on average). They mentioned the highest number of tragic events (10 on average) in their interviews, with a very high number of family members lost to political repression (0.9). This implies that almost each participant had lost at least one family member because of a political arrest. They also dated their earliest memory quite late - at age 6, on average - which may be a manifestation of childhood amnesia. In addition, they showed a very low level of resilience under stress, a rather high level of depression and an average level of general life satisfaction in old age (at the time of their interviews). Only this group showed a high percentage of negative early childhood memories. Perhaps this is the point where their childhood trauma revealed itself.

The major conclusions drawn from the quantitative analysis could be formulated as follows:

- A majority of early childhood re-collections were positive: often they were about doing something associated with parent(s) or playing with other children; about father coming for a short visit; about somebody bringing home food; and about other important gifts, such as a first book. The negative memories included mother's crying, or in other cases her numbness; and hearing that war had broken out. For example, 4-year-old Zina stated that during the Siege "a huge rat sat on the cold stove in the kitchen and looked at me with arrogance."

- The suffering of both groups of children was different, if the suffering could be compared. The experimental group (that remained in Leningrad) reported that the most difficult things for them, apart from hunger, bombings and cold, were the visibility of death; the darkness during the long winters; death or fear of death for family members; fear of being killed or harmed by other people; fear of staying alone; and helplessness. 
- The experimental group showed statistically significant differences in their emotional state in their present life, namely a higher level of resilience under stress and life satisfaction. Contrary to one of our initial hypotheses, they did not show a higher level of depression than control group (the evacuees).

- Are the now-adult experimental group ('blokadniki') victims more emotional about their childhood during the Siege? First of all, the volume of verbal material that they provided in interviews was significantly higher (3-6 times) than the material provided by the control group. This might be because their wartime trauma was officially recognized and accepted by Soviet society, while that for the control group was not.

- The process of initially recruiting participants showed that at least onethird of those approached were not yet ready to openly discuss their Siege experiences. Silence remained a safe shelter for them, as it had been for concentration-camp survivors after World War II.

- Beyond the children's war experience, a few other factors revealed themselves as important: the child's age at the outbreak of the war; the length of time the child remained in the blockaded city; and the number of traumatic events experienced or remembered.

\section{Content Analysis}

The elements of trauma, found in the children's stories, often remained hidden from the individual subjects. The latter, however, though out of contact with their suppressed feelings, did have a vague sense that the events described were not simply details of the wartime way of life.

When the subject identified strongly with the lost object or when the child merged with the object, he/she could experience the feeling of dying or annihilation. In fact, many current survivors are still unable to talk about their childhood experiences. At least for part of them, this 'reactive mechanism' demonstrates a defensive rejection of their past and an inability to cope with the 'Siege' topic.

A recent discussion on 'trauma understanding' supports the psychoanalytic concept that the 'encapsulated trauma' has a negative restrictive effect on a person's life and leads to psychic retreat (De Steiner, 1993). Split-off elements of traumatic experience become unconscious, often forcing the person to lose direct contact (memory) with them. Nevertheless these split-off elements can be recognized in actions and physical symptoms; they even cause the quality of psychic reality to deteriorate. One way of relating to suppressed material would be to remember it subconsciously. This method would enable these elements of trauma to stay alive but not permit the person direct access to them. Consequently, they would assume a more bearable (less painful) character.

This document revealed that Siege survivors demonstrate elements of their trauma fixation in adult life. Nevertheless they are aware of their vulnerability and fragility; they also display a high level of emotional sensitivity and empathic understanding of others. 
One of the first traumas that children are exposed to is the loss of a significant other, called 'object-loss' phenomenon. Anna Freud, who worked with traumatized children during and after World War II, stressed that children subconsciously could use regressive behavior instead of contact with their actual feelings if the latter felt intolerable. This is one of the few ways for a child to withdraw his own feelings (Jacobson, E., Spitz, R.A., Waelder et.al., 1954, p. 67). Other publications also have confirmed this observation. For example, Green and Kocijan-Hercigonja (Green, Kocijan-Hercigonja, 1998) have explored coping mechanisms in children traumatized by war, noting that 'these children are vulnerable to post-traumatic stress disorder (PTSD), phobic anxiety, depression, and alienation'. Macksoud and Aber, for their part, found that exposure to violent activities (such as shelling or militia fire) caused the deepest trauma that children experienced during the war in Lebanon. Moreover, these authors have argued that 'some children become extremely disorganized after being exposed to a direct war trauma' (Macksoud, Aber, 1996, p.74). All of the aforementioned 'negative' symptoms, particularly alienation and disorganization, could be viewed as a form of regression. Our findings, however, did not support this conclusion. One of our participants (O.N., aged 22 at outbreak of War), achieved a promising career during the war. He stated, when asked directly, that institutionalized children had not shown regressive tendencies in their behavior. They had, in fact, stressed an opposing tendency: psychologically, war children had matured rapidly, following the adults 'heroic patterns of behavior'. This rapid maturation had helped them to survive.

On a theoretical plane, however, war trauma could be used to explain not only the dissociation of mind (Fonagy, Target, 1995), but also the principal phenomena of borderline conditions in children. For example, a child had not developed trust in adults because he had not been protected against mental and physical pain. Moreover, the anxiety and aggression of such an unprotected child had remained untamed. The child, in consequence, had not learned to resolve his/her love-rage conflict because his/her beloved mother had not addressed the child's basic requisites to be fed, loved, heard and understood. As a result, his/her self-esteem had deteriorated, leaving the child to experience loneliness since he/she was not important enough for his mother.

Other Leningrad children and their mothers, by contrast, have shown extremely intensive bonds of mutual identification. These could partially be explained by the fact that the Ego boundaries of both had weakened due to various strong deprivations causing the distinctions between self and object to blur. But in many other cases, they had exhibited real devotion to each other.

In many cases the interviews showed that a mother was psychologically present ('internalized') in a child's mind and this assisted him/her to survive war-associated sufferings. Other children had conceived an individual explanation of this war-related enigma, with this helping them to survive. Even the loss (death) of a loved one or loving person could be a maturing experience, often associated with an increased capacity for empathy, caring for others and being altruistic. One Leningrad girl, for instance, had organized her father's and her own evacuation; they survived the ordeal and even met the mother after the 
war when this woman was released from her camp (Alexandra Vladimirovna, aged 11 at outbreak of war, was interviewed in 2004). This life story reminds the reader of Winnicott's concept of a 'holding environment': once learned and internalized by the child, it could later on be used by him/her for survival (Winnicott, 1960). This story gives remarkable illustrations of other psychoanalytic concepts, such as Kohut's 'mirroring response', when a mother's understanding and correct response to her child's feelings helps the child to feel he/she exists (Kohut, Wolf, 1978).

Our study has shown that the meaning of trauma has broad variations. The initial study design - a comparison of two groups of children (experimental group, or Siege survivors; and control group, or evacuation survivors) - has provided limited results. For both groups, the number of losses (regardless of how the child survived the war) seems to be the most significant factor that has shaped their level of traumatization. Some children who had lost parents showed no signs of arrested development and could be sublimating trauma through positive achievements. Others, by contrast, might still be fixated at the point of trauma. The trans-generational transmission of war trauma (Fonagy, 1999) could be viewed in such phenomena as oversensitivity toward war-associated topics among some adult children of survivors; 'food anxiety' among others; and behavioral changes, such as specific war-related phobias, among people born after the war.

\section{Acknowledgements}

I would like to express my gratitude to Ludmila Kosenko and Irina Rudenko, for their help in collecting the data, and to Howard Goldfinger, for translating the interview materials from Russian to English. The International Psychoanalytical Association (IPA) Research Board assisted me by funding the final year (2009) of this project.

\section{References}

De Steiner, M., C. (1993). Children and their Dreams. International Journal of Psycho-Analysis, 74, p. 359.

Fonagy, P. (1999). The transgenerational transmission of holocaust trauma. Lessons learned from the analysis of an adolescent with obsessive-compulsive disorder. Attachment and $\mathrm{Hu}$ man Development, 1, pp. 92-114. doi: 10.1080/14616739900134041

Fonagy, P., Target, M. (1995). Dissociation and trauma. Current Opinions in Psychiatry, 8, pp. 161-166. doi: 10.1097/00001504-199505000-00006

Green, A.H., Kocijan-Hercigonja, D. (1998). Stress and Coping in Children Traumatize by War. Journal of the American Academy of Psychoanalysis, 26(5), pp. 85-597

Jacobson, E., Spitz, R.A., Waelder, R., Davison, C., Bell, A., Mittelmann, B., Mahler, M.S., Bychowski, G., Kris, E., Greenacre, P., Freud, A., Hartmann, H., Lewin, B.D., Escalona, S., Loewenstein, R.M. (1954). Problems of Infantile Neurosis-A Discussion. The Psychoanalytic Study of the Child, 1954, 9, pp. 16-71. 
Kohut, H., Wolf, E. (1987). The disorders of the self and their treatment: An outline. International Journal of Psycho-Analysis, 59, pp. 413-426.

Macksoud, M. S., Aber, J. L. (1996). The war experiences and psychosocial development of children in Lebanon, Child Development, pp. 67-88.

Winnicott, D. W. (1960). Ego distortion in terms of true and false self. In: Maturational Processes and Facilitating Environment. New York: International University Press, 1965, pp. 140-152.

Received: 14 March 2013

Accepted: 30 октябрь 2013

Available online: 11 November 2013 